\title{
LEITURAS SOBRE A CONDIÇÃo FEMININA NO LAR DOS Vicentinos, em Rio Branco, Acre ${ }^{1}$
}

Patrícia Carvalho Redígulo

RESUMO: A partir de documentos coletados em prontuários médicos, registros e históricos arquivados no Hospital de Saúde Mental do Acre - HOSMAC, bem como os dados das fichas de admissão e documentos arquivados nas pastas individuais mantidas pela Sociedade São Vicente de Paula procura-se dialogar com as vozes "silenciadas" das mulheres que vivem no Lar Vicentino, na cidade de Rio Branco, na Amazônia acreana. Nesse diálogo, o foco é traduzir e compreender os sentidos e significados das trajetórias dessas mulheres, na perspectiva de produzir uma leitura sobre a condição feminina em específicas condições de vida no interior de um asilo numa cidade que vem sendo promovida como um dos melhores lugares para se viver na região norte do Brasil.

PALAVRAS-CHAVE: Condição Feminina. Trajetórias. Asilo. Rio Branco. Amazônia Acreana.

O que é um lar? Onde está o lar? Realmente existe o lar ou é uma construção de sentidos e significados que perseguimos ao longo da vida, a cada dia, a cada relação que fazemos e desfazemos. Etimologicamente lar em latim lare significa: a parte da cozinha onde se acende o fogo, semelhante a uma lareira. Utiliza-se figurativamente a palavra lar para designar a casa de habitação de uma família; ou para referir-se ao torrão natal; a pátria. Indicar ainda o ninho ou toca de animal. Além disso, lar ou lare também pode assinalar a superfície da prensa onde assenta o vinhaço ou o lar do pão, isto é, a parte do pão que assenta sobre o lar do forno. Portanto, o termo: lar se entrelaça a muitos significados que se relacionam, tais como: casa, família, calor, pão, alimento, lugar de nascimento. ${ }^{3}$

Talvez, o lar esteja presente na espera, que um dia se realize

\footnotetext{
Texto originalmente apresentado como parte da Dissertação de Mestrado "Diálogos, vozes e deslocamentos sociais: trajetórias de residentes do Lar Vicentino, em Rio Branco - Acre”, defendida no ano de 2011 junto ao Programa de Pós-Graduação em Letras: Linguagem e Identidade, da UFAC.

2 Mestre em Letras: Linguagem e Identidade, Professora da FAMETA - Acre.

3 Dicionário Aurélio de Língua Portuguesa.
} 
o sonho, de casa, família, calor, pão, alimento. No entanto, o termo também está marcado pela falta, carência ou incompletude. Há sempre e ao menos um pouco de solidão presente; de ausência; saudade; um cheiro, um som, uma luz, uma alegria, esperança, espera, algo que nunca se completa. Uma infância. Muitas imagens, muitas vozes. Algo que prende e sufoca, acolhe e acalenta, nutre e fortalece, rompe e se desfaz. Um lar é feito de relações com o outro e consigo mesmo.

Das razões e dos porquês, muitas pessoas transformam o Lar Vicentino em seu próprio lar e na perspectiva de desconstruirmos mitos e falsas imagens, recorremos às palavras de Tereza Ponce Capóia, 72 anos, moradora do Lar:

Meu filho, muito doente, foi transferido do Hosmac- Hospital de Saúde Mental do Acre para o Lar Vicentino. Eu não tinha para onde ir e aceitei o convite da diretoria para viver nesse lugar. Muitas pessoas acham que nós vivemos aqui abandonados, que os funcionários se aproveitam do nosso dinheiro, isso aqui não existe. Esse é nosso lar, e não é pelo nome da casa não, é porque onde existir respeito, carinho, comida e amor esse é um lar de verdade, e isso nós temos muito. Gostaria muito de voltar a viver na colônia, lá tudo é bom. Sinto muita falta de quando podia trabalhar no que era meu, mas também me dói muito lembrar como as pessoas são malvadas e não se importam em deixar uma anciã no fim da vida sem um teto para chamar de seu. Mas isso tudo agora é passado, a vida que levamos aqui é muito boa, essas meninas são verdadeiros anjos para nós. ${ }^{4}$

Tereza foi entrevistada pelo jornal O Rio Branco, no momento em que se comemorava um ano de serviços prestados pela nova coordenação, que havia sido instituída por ordem do Ministério Público, em virtude das denúncias sobre a antiga administração. Convidada a falar, a entrevistada defende a vida no lar Vicentino e conceitua: "Esse é nosso lar, e não é pelo nome da casa não, é porque onde existir respeito, carinho, comida e amor esse é um lar de verdade, e isso nós temos muito".

No entanto, Tereza segue e diz que "gostaria muito de voltar a viver na colônia, lá tudo é bom”. Conceitua o que é um lar para si mesmo, e tenta encontrá-lo, na instituição. No lar vicentino nem tudo é bom para Tereza,

\footnotetext{
Tereza Ponce Capóia, entrevista concedida em 06/04/2010.
} 
ela não se sente em casa, sente falta de trabalhar no que é seu, de ser respeitada, ter carinho, comida e amor. Ela modifica o teor da sua fala quando está em uma entrevista "mais oficial".

Ao entrevistar Tereza, ${ }^{5}$ em uma tarde nublada e chuvosa, ela estava sentada em sua cadeira de balanço. Seu aparelho televisor sempre ligado, como um companheiro cúmplice e atento; ela relata sua vida no campo, as experiências de trabalho por inúmeros lugares, tais como: São Paulo, Paraná, Mato Grosso, Rondônia e Acre.

Filha, esposa, mãe e trabalhadora rural, esta tem sido sua vida, sempre no campo. Trabalhou nos canaviais do Paraná, onde foi muito feliz. Lembra com saudade das aventuras no trabalho, a convivência familiar, a relação com seu esposo, as peripécias dos seus netos. Conta com tristeza como perdeu a colônia, após a morte do marido e do filho mais velho, e como foi espoliada pela nora.

Convidada a morar com uma amiga e sua família, Tereza recusou, explicitando suas razões:

Não, Nunca. Pode ser o que for, por mais boa que seja a pessoa, nunca, né? É mió morá sozinha, do que... Uma hora tá mais enjoada, outra hora é mais... É por que a pessoa é diferente. Aí ela... Nunca é igual à casa da gente.

Durante a entrevista a funcionária do lar traz o lanche da tarde, cujo cardápio é composto de um copo de vitamina e biscoitos. Pergunto se deseja fazer sua refeição e Tereza faz uma expressão de contrariedade, dizendo:

eu num gosto desta vitamina não, me repuna (repugna). To mal do estômago, num to comendo direito. Aqui, Deus me perdoe falar, num tô reclamando, mais aqui a comida num tem gosto, num tem tempero, é sem cor. Eu já falei, já mudaram num sei quantas vez a cozinheira, mas num tem jeito. Eles colocam coentro em tudo. Num usam salsinha, né, que nem nóis usa, num usa um pouquinho de colorau. Deus me perdoe falar! Quando eu vejo aquela carne muída branca, num consigo comer ela não. Que saudade de um bife bem passadinho com salsinha, bem temperadinho... aqui eles serve uma farofa de ovo é

\footnotetext{
Tereza Ponce Capóia, entrevista concedida em 06/04/2010.
} 
boa, mais é muito seca difícil de comer. Deus me perdoe num quero reclamar de comida não, mas... (...) Na roça, criá porco... Quando davam oito horas da noite, dava vontade de comê leitoa "Ai que vontade de come uma leitoa veia assada! Ah!" Num tinha nada que vê quarqué hora da noite, matava uma leitoazinha lá. A que tivesse mais gordinha... Ah Meu Deus! Num fala. ${ }^{6}$

Ao ler o depoimento de Tereza, concedido ao jornal O Rio Branco, observo o modo como a entrevistada responde ao jornalista. Faz uma avaliação do lar Vicentino, mas não deixa de mostrar suas intenções e desejos. Ela sabe o porquê, para quem e como deve falar ao jornal, sobre o lugar em que vive atualmente.

Admiravelmente polida, mas jamais ingênua ou acrítica Tereza se posiciona sobre sua condição de moradora do lar. No entanto, não deixa de expor seus sonhos, seus desejos para outra vida. Porém, na entrevista que me concede, sua atitude é de abertura, confiança, empatia, reciprocidade. Sinto um alargamento dos horizontes. Tranqüila e alegre, ela tece com singularidade, suas recordações e lembranças. Mas, essa singularidade tem os limites:

da cultura do próprio tempo e da própria classe. Assim como a língua, a cultura oferece ao indivíduo um horizonte de possibilidades latentes - uma jaula flexível e invisível dentre da qual se exercita a liberdade condicionada de cada um (GINZBURG, 2006, p.20).

O exercício da liberdade de Tereza com a palavra, a partir dos horizontes de suas possibilidades, de sua cultura; do tempo presente, com as particularidades de seu modo de falar, de pensar, sentir e significar, re-elabora suas lembranças; as experiências vividas; as dores e alegrias sentidas. O lar de Tereza está dentro dela própria, ela mora em si mesmo, sendo seu lar, mais que físico, ou seja, é um lar feito de memória; de sentimentos e de uma belíssima história de vida. Tereza habita suas raízes. Assim observa José Gonçalves Filho:

As experiências só nos alimentam na medida em que as construímos, mas, em certa medida, uma raiz nos tem a nós mais do que nós a ela. Não produzimos nossas raízes, nem somos meros reflexos delas: nós inventamos nossas raízes à medida que as habitamos (GONÇALVES FILHO, 1991, p. 14).

Idem. 
Embora vivendo em uma instituição asilar, Tereza não se deixa levar por opiniões alheias, ou condições estabelecidas. Ela participa, escolhe, lembra, fala, avalia, analisa criticamente as pessoas, o funcionamento da casa.

Tereza se rebela ao compreender que deve dominar as diversas formas do discurso, para se defender e defender a imagem do lugar onde vive atualmente: seu lar provisório. Assim o discurso que Tereza faz ao jornal é muito diferente do que expõe a mim na entrevista. Ela se permite com astúcia utilizar maneiras distintas para declarar algo.

Para o veículo de informação, o jornal, que pretende divulgar as "verdadeiras" condições de vida dos moradores do lar Vicentino, Tereza diz aquilo que considera "certo", "apropriado" e "permitido" dizer. Durante a entrevista sente-se autorizada a criticar, dizer o que não lhe agrada, comparar seu lar e o atual; avaliar a qualidade da alimentação servida aos residentes, e assim por diante.

Os novos sujeitos do "novo" passado são "caçadores furtivos" que podem fazer da necessidade virtude, que modificam sem espalhafato e com astúcia suas condições de vida, cujas práticas são mais independentes do que pensaram as teorias da ideologia, da hegemonia e das condições materiais, independentes, inspiradas nos distintos marxismos. No campo desses sujeitos há princípios de rebeldia e princípios de conservação da identidade, dois traços que as "políticas públicas" valorizam como auto-constituintes (SARLO, B. 2007, p.16).

É nessa perspectiva que compreendo os sujeitos da pesquisa, ou seja, os considero como os "novos sujeitos" que transformam suas vidas de modo criativo, inteligente e crítico.

Indivíduos participativos, os quais produzem de modo inventivo outras possibilidades, a partir de situações adversas, são conscientes de suas escolhas no campo onde se situam, negociam, transgridem e re-criam novas formas e atitudes, bem como se rebelam e também conservam seus modos de vida.

As histórias de vida e testemunhos não são reconstituições tranqüilas do passado. Seguindo a perspectiva adotada por Walter Benjamin, é 
preciso destacar que o passado é um campo conflituoso, um campo de disputa onde estão em jogo desejos e vontades, bem como a subjetividade e a perspectiva de quem os reconstrói a partir da experiência do presente (BENJAMIN, 1993). A "subjetividade também é histórica" (SARLO, 2007), pois se faz e se re-faz na experiência e no tempo.

As contradições, conflitos e conciliações estão presentes no Lar Vicentino assim como estão em qualquer espaço onde há um grupo de pessoas que convivem e que necessitam da relação próxima com o outro. As diferenças estão presentes e é preciso que estejam, pois, trata-se de sujeitos com vontades e desejos diversos. Talvez uma alternativa possível seja lançar um olhar com atenção e interesse para cada um desses sujeitos e questionar quais são suas carências, urgências, necessidades, sonhos e projetos.

Somos seres fundamentalmente necessitados de participação e qualidades. Justamente por isso, quando somos historicamente obrigados a viver em uma cidade, que fere nossa capacidade de participação (...) e também fere a nossa capacidade de nos relacionarmos qualitativamente com as coisas e com as pessoas (porque o sentido das coisas e dos laços sociais se reduz a valores meramente econômicos), nesses contextos tão adversos à participação, nesses contextos de desqualificação, morremos um pouco, se não morremos completamente, mesmo tendo às vezes o que comer (GONÇALVES FILHO, 1991, p.16).

Não basta o alimento, nos alerta Gonçalves Filho, descortinando questões de fundo, também, subjacentes ao presente estudo. Ao adentrar no Lar Vicentino, inicialmente, empreendo uma busca de um sentido para minha pesquisa e encontro um mundo, ao mesmo tempo, desconhecido e familiar; ao me colocar como interlocutora daqueles que me permitem entrar em suas vidas, torno-me uma referência para que expressassem suas angústias, alegrias, tristezas e buscas de afeto. Dessa forma passo a ser cobrada e mesmo confundida com aqueles que deveriam lhes dar assistência.

Nesse processo passo a viver e a tratar de uma dificuldade, um enigma, o encontro com algo desconhecido; tento fazer uma análise da difícil relação com o "outro", quando este "outro" não pode dizer em palavras o que 
lhe vai à alma. Apreender a ouvir e ver, observar olhares e gestos, ou pequenas frases desconexas, fragmentos que podem auxiliar e indicar o caminho. Essa condição é acentuada, talvez ao extremo, quando se fala das mulheres que vivem no Lar Vicentino.

Durante a pesquisa o encontro com elas, por razões inconscientes, foi evitado. Mas o distanciamento e a passagem do tempo propiciam caminhos não previstos e o completamente imprevisível, não planejado entre em cena. Cada momento é único, cabendo ao pesquisador capturá-lo no instante. É nesse diapasão que apresento as mulheres do Lar dos Vicentinos, bem como a maneira que "invento" para compreendê-las ou compartilhar instantes vividos em suas companhias.

\section{Quem são as mulheres do Lar Vicentino?}

As mulheres do Lar Vicentino são pessoas com um longo histórico de internação em instituições de saúde. Mulheres que foram transferidas para o lar Vicentino, vindas do Hospital de Saúde Mental de Rio Branco (Hosmac). São treze mulheres internas na casa, sendo que a primeira vista, são muito semelhantes entre si, em seus vestuários e maneiras: vestidas com seus camisolões de algodão com cores claras, cabelos cortados a la garçon, olhares perdidos em horizontes diversos e longínquos, rostos "abobalhados" e sorrisos "pueris".

Confesso que quando as vejo pela primeira vez, não sinto qualquer interesse em conhecê-las, simplesmente não me causava curiosidade para empreender um estudo sobre suas vidas, ou sua condição, com o tempo e a vivencia da pesquisa de campo me aproximo, o que me desperta certa curiosidade, mas, não ainda ao ponto de traçar um plano de inseri-las neste estudo. As questões pontuadas no momento do Exame de Qualificação foram oportunas e estimulantes para dar um passo nessa direção.

Entretanto, como compreender o mundo de quem ali vive, apenas a partir das análises de quem pode narrar sua experiência? E aquelas que não podem narrar? Como construir um estudo em que as próprias mulheres tivessem a oportunidade de se expressar? Novas dúvidas, muitas incertezas que 
procuro "resolver" intuitivamente, posto que lidar com "as mulheres" me era um desafio improvável, um verdadeiro "problema” de pesquisa.

Como estava à procura de histórias de vida narradas pelos próprios sujeitos e sustentadas pela construção/desconstrução de suas memórias, identidades e significados de suas culturas, dialogar com "as mulheres" era para mim considerado impossível, e talvez pouco interessante.

Como posso compreender essas mulheres e suas histórias? A partir de que perspectiva o diálogo pode ocorrer? Como ouvi-las, sem recorrer às narrativas de "outros", como: médicos, enfermeiros, funcionários, familiares?

Não há respostas acabadas, resoluções e justificativas, no entanto, para mim essas mulheres são enigmas, e, decifrá-las, compreendê-las, tentar construir uma "ponte", através do dialogo organizado a partir de outra lógica, outro sistema, a partir de seus gestos, olhares, atitudes, pequenos relatos, observando seus quartos e objetos pessoais, talvez seja um caminho possível.

Decido colher "cacos", pedaços de histórias, fragmentos de seus cotidianos, observar atitudes, movimentos, maneiras de ser e agir.

\section{Prontuários, receitas encaminhamentos: leituras e interpretações}

$\mathrm{O}$ arquivo do lar Vicentino fica em uma pequena sala, à direita de quem entra no prédio, na qual funciona, também, a recepção e a sala da administração, é o local onde pesquiso sobre as mulheres. No arquivo, em gavetas de metal, estão ordenadas as pastas individuais. Solicito autorização para a leitura e a jovem secretária me oferece uma mesa com cadeira para que eu possa fazer minhas anotações.

Seguindo minhas anotações, percorrendo as trilhas do discurso médico, avanço em meio aos prontuários de outras mulheres que vivem no Lar dos Vicentinos. Nesses prontuários, observo que, as mesmas apresentam históricos com alguns pontos em comum. O grupo observado compreende treze mulheres. A idade delas variam entre 52 à 103 anos. Cinco delas são viúvas e oito solteiras; duas foram encaminhadas ao asilo pelas famílias; cinco transferidas do Hosmac e três foram encaminhadas pelo serviço social do governo do Estado do Acre. Dez dessas mulheres são analfabetas e três cursaram até o terceiro ano do 
Ensino Fundamental. Três delas apresentam problemas dificuldades na fala; uma com paralisia infantil e problema na fala; nove com transtornos mentais graves; uma não há registro e uma apresenta apenas problemas na coluna. Todas são aposentadas e contribuem com $70 \%$ de seus rendimentos para o pagamento da mensalidade do Lar Vicentino.

Os dados descritos foram coletados diretamente dos históricos e registros médicos arquivados no Hosmac, ${ }^{7}$ bem como em fichas individuais e contratos de prestação de serviço arquivados na entidade. Os dados são frios, "verdadeiros" em sua "cientificidade".

Transcrevo a seguir trechos dos registros pesquisados, de cada uma dessas mulheres. A fim de resguardá-las, garantindo o direito de sigilo de suas identidades, seus nomes foram por mim alterados.

Cremilda: nascida em 20 de abril de 1944. Deu entrada no lar em 02 de julho de 2007. Não há registro do seu estado civil; não-alfabetizada; aposentada. Foi encaminhada pelo filho. Tem uma procuradora para administrar seu benefício (aposentadoria). Consta registrado em arquivo: termo de declaração da Promotoria Especializada de Defesa da Cidadania, o termo trata de questões relativas a aposentadoria de Cremilda, que era administrada por sua irmã, a mesma, obrigada por força da lei comprometeu-se em entregar o cartão de aposentadoria na administração do lar.

Célia: nascida em 24 de maio de 1959. Solteira, não alfabetizada, aposentada. Célia foi internada no lar por sua família, está aposentada. Segundo laudos médicos apresenta paralisia infantil desde os dois anos de idade, não fala, anda com dificuldade, pois tem o lado esquerdo da face paralisado. Nos documentos pesquisados no Lar Vicentinos consta o registro de que Célia tem "problemas" com sua irmã que utiliza seu cartão de benefícios. Também consta uma ocorrência judicial (estelionato) e registros bancário onde se vê que foram efetuados empréstimos na conta-benefício (aposentadoria)

Guiovanda: nascida em 27 de maio de 1952. Solteira, tem dois filhos. Não-alfabetizada é aposentada. É egressa do Hosmac, onde recebeu alta em setembro de 1998. Apresenta um longo histórico médico de controle

Dados pesquisados no Serviço de Arquivo Médico e Estatístico - SAME do Hospital de Saude Mental do Acre. Período: 23/05 à 31/05/2011; Responsável pelo arquivo: Lourdes Araújo; e apoio técnico de Marilza da Silva Lopes, técnica de enfermagem. 
de tratamento. Ela foi diagnosticada como portadora de psicose não-orgânica e esquizofrenia. Foi re-internada diversas vezes, sendo encaminhada para o Lar Vicentino, em 31 de agosto de 2002. Em seu histórico está registrado que não possui respaldo familiar; apresenta um estado mental estável; não é dependente para a realização de sua higiene pessoal e alimentação. Atualmente é beneficiada com o Amparo Assistencial da Lei Orgânica da Assistência Social (LOAS), consistente de salário mínimo. Há em seu arquivo o contrato de prestação de serviços do Lar Vicentino, onde se prevê o pagamento mensal correspondente a $70 \%$ de seus rendimentos.

Nos arquivos do lar vicentino, consta o registro de observações da assistente social do HOSMAC, encaminhado para o lar, assim diz: Avaliação técnica - a paciente apresenta um estado mental estável, não é dependente para a realização de sua higiene pessoal e alimentação. Atualmente é beneficiada com o Amparo Assistencial da Lei Orgânica de Assistência Social - LOAS, que consiste em um salário mínimo. Há também um contrato de prestação se serviços do lar dos vicentinos, em nome de Guiovanda.

Maria Adélia: nascida em 5 de agosto de 1908. Aposentada. Segundo informações na ficha de admissão do Lar vicentino, a mesma não anda e necessita de cuidados para sua higiene pessoal, alimentação e locomoção. Não há maiores detalhes em seu histórico. Seu registro de nascimento foi expedido por ordem judicial, em 13 de março de 2007.

Romilda: nascida em 12 de maio de 1954. Solteira, aposentada, não-alfabetizada. Saiu do Hosmac em 3 de setembro de 2009, encaminhada para o Lar Vicentino. Segundo consta em seus registros médicos, se encontra em tratamento ambulatorial no Hosmac, e no momento tem prescrição de psicofarmacos (medicamentos para doença mental). Paciente esquizofrênica grave, esteve internada em condição de residente no Hosmac no período de 23 de fevereiro de 1979 a 3 de agosto de 2008, data em que foi encaminhada para o lar vicentino. Não tem condições laborativas e de praticar atos da sua vida civil. ${ }^{9}$

Maria: nascida em 18 de março de 1941. Solteira, não-alfabetizada. Transferida para o Lar Vicentino, em 31 de agosto de 2007. Sua primeira

$\checkmark$ LEI no 8.742, de 7 de setembro de 1993. Dispõe sobre a organização da assistência Social e dá outras providencias.

9 Atestado pelo Dr. Mauro Hashimoto, médico psiquiatra do Hosmac. 
internação no Hosmac foi em 7 de outubro de 1986. Diagnosticada com esquizofrenia, não possui ficha individual de admissão no lar ou qualquer registro mais detalhado.

Terezina: nascida em 4 de novembro de 1943. Viúva, não-alfabetizada, aposentada. Deu inicio ao tratamento médico em 5 de fevereiro de 1981, no Hosmac com diagnóstico de esquizofrenia. Segundo atestado médico consta que: "é portadora de transtorno mental crônico e grave. É incapaz definitivamente para exercer atividades laborativas e de praticar atos da sua vida civil". Foi transferida para o Lar Vicentino nesta mesma data. Sua filha está internada no Hosmac, na condição de residente, desde 24 de outubro de 1994.

Mariana: nascida em 12 de julho de 1944. Viúva, não-alfabetizada, aposentada. Foi encaminhada para o Lar Vicentino pela família. Os médicos a diagnosticaram como portadora psicose não-orgânica não-especificada. ${ }^{10}$ Em sua ficha de admissão no lar consta que a residente é acamada, não anda, e necessita de cuidados para higiene, alimentação e locomoção.

Marialva: nascida em 20 de agosto de 1941. Casada, alfabetizada, encaminhada ao lar por entidade de assistência social sem identificação. Não há um registro mais detalhado em seu histórico, apenas uma declaração onde se lê que sua irmã veio ao Lar Vicentino entregar seu cartão de benefícios, com senha, aos cuidados da administração da casa, datado de 10 de janeiro de 2010 .

Marizete: nascida em 25 de dezembro de 1917. Viúva, funcionária pública aposentada, cursou até a $3^{a}$ série do Ensino Fundamental. Foi encaminhada ao lar pela família. Ficou nesse asilo até 9 de novembro de 2010, quando saiu pela primeira vez, retornando em 3 de janeiro de 2011. Em 4 de março de 2011, foi entregue aos cuidados da família.

Mirele: nascida em 19 de agosto de 1937. Consta registrado

10 Segundo o Código Internacional de Doenças - CID-10 - conceituado para padronizar e catalogar as doenças e problemas relacionados à saúde, tendo como referência a Nomenclatura Internacional de Doenças, estabelecida pela Organização Mundial de Saúde, a psicose não-orgânica significa que não é causada por uma doença clínica, mas sim por uma doença mental. Há várias doenças nesse grupo. Agora, todas as doenças mentais que possam ter sintomas psicóticos são chamadas não orgânicas (esquizofrenia, bipolar, depressão grave, etc). 
no arquivo do lar uma declaração onde se lê: que sua irmã veio ao lar para fazer a entrega do cartão de benefício com a senha, à instituição administrativa lar vicentino. Datado em 10 de janeiro de 2010.

Tereza: nascida em 21 de dezembro de 1937. Viúva, trabalhadora rural aposentada. Estudou até a $3^{\text {a }}$ série do Ensino Fundamental. Passou a viver no Lar dos Vicentinos, encaminhada pelo Serviço Social do Hosmac, onde seu filho estava internado. Foi despejada de seu lar, tendo que viver em uma moradia emprestada na cidade de Acrelândia (Acre). Em virtude da doença mental do filho mais novo e das condições precárias e insatisfatórias em que vivia naquela cidade decidiu residir no Lar Vicentino.

Elvira: nascida em 13 de agosto de 1952. Solteira, não-alfabetizada e aposentada. Em 11 de novembro de 1979 registra-se a primeira internação. Não há histórico ou registro detalhado, somente em: 14/03/2007 - "queda em só nível com ferimentos do couro cabeludo. Foi feito um "raio-x" (exame médico). Encontra-se, em anexo, alguns receituários com prescrição de medicamentos. Não há registro do histórico da paciente, apenas diagnósticos de doenças, segundo o Código Internacional de Doenças - CID 10 - como por exemplo: F80 (transtornos específicos de desenvolvimento da fala e da linguagem); F72 (retardo mental grave); F71 (retardo mental moderado); F 29 (psicose não orgânica não-especificada)

Anexado aos documentos de Elvira, consta um laudo médico no qual se lê que ela: “... é portadora de deficiência mental grave, pueril, deficiência física. É incapaz de exercer atividades laborativas para prover meios para sobrevivência. Necessita de benefício da Previdência Social". ${ }^{11}$

Essas mulheres são uma representação do esquecimento, do silenciamento na construção de uma memória oficial que descarta certas versões, menos atraentes, na construção da história que se quer como única. A imagem das mulheres representa a possibilidade de mergulhar no desconhecido, em lugares subterrâneos e escuros; uma possibilidade de "escavação interior" em busca de compreensão e descobertas sobre a vida, sobre a alma humana.

$\pi$ Dr. Mauro Hashimoto, 08/10/2008. Laudo médico - Serviço de Arquivo Médico e Estatístico - SAME. Hospital de Saúde Mental do Acre - HOSMAC. Responsável pela documentação: Sra. Lourdes Araujo. Pesquisa realizada em 31 de maio de 2011. 
Trata-se da atitude semelhante àquele que chega pela primeira vez a um país distante e se depara com uma cultura desconhecida, "estranha" e diversa da sua realidade, mas que, aos poucos, a partir das relações vivenciadas percebe o quanto há semelhanças em si; pode ser uma experiência carregada de sentimentos e impressões transformadoras, tais como: o medo, a solidão, o vazio, a doença, a mudez, mas também a doçura, a ingenuidade, a bondade, o carinho, a gentileza, a curiosidade, a ânsia de viver.

Em uma tarde ensolarada e comum, no Lar Vicentino, três mulheres estão sentadas na grande mesa da entrada da capela, acompanhadas da professora. Naquele local são realizadas as atividades de pintura com giz de cera, recorte e colagem; a participação de todos é facultativa. Elas estão colorindo desenhos traçados pela professora. Dirijo-me até elas, cumprimento-as. Elas sorriem e me contam as "novidades".

Pergunto a Célia o que aconteceu com seu braço e seu olho esquerdo, pois há hematomas em seus braços. Célia não fala, gesticula, balbucia, aponta. Alguém diz: "Ela está dizendo que caiu no banheiro, ensaboou muito o corpo e caiu; não quebrou nada; foi atendida, levada ao hospital, não sofreu lesões graves". Pergunto se ela estava sozinha e ouço como resposta que "sim, estava. Ela toma banho sozinha." Célia sorri para mim, e continua sua "narrativa" sobre o acidente.

A partir desse contato e após todo um levantamento de documentos escritos sobre o deslocamento dessas mulheres para o asilo, percebo questões significativas para a compreensão da condição feminina no lar.

Após a leitura dos documentos arquivados no Hosmac e no Lar Vicentino, penso em Célia, nas marcas deixadas pelo acidente no banheiro; divago sobre os cuidados que temos com os recém-nascidos, todos os procedimentos para o banho, a troca de roupas, a alimentação, e como sustentamos suas mãos aos primeiros passos. Então penso na desenvoltura de um corpo adulto, forte, saudável, que realiza movimentos automáticos, acostumados as atividades cotidianas. Volto a imaginar Célia no banheiro, enquanto leio os registros, históricos e os prontuários médicos:

Célia. Nascida em 24 de maio de 1959, solteira, não-alfabe- 
tizada, aposentada. Foi encaminhada pela família para o Lar Vicentino. Segundo laudo médico apresenta paralisia infantil. Não fala, anda com dificuldades, pois tem o lado esquerdo paralisado. Consta em sua ficha o registro de um termo de declaração, expedido pela Promotoria Especializada de Defesa da Cidadania, onde se lê que sua irmã administradora de sua aposentadoria estava fazendo uso indevido de seus rendimentos mensais. Por essa razão foi obrigada, judicialmente, a entregar o cartão de benefícios à administração do Lar Vicentino, principalmente, porque Célia, agora, encontra-se sob a responsabilidade dessa instituição. $^{12}$

O que posso apreender sobre Célia? Posso compreendê-la? Sim, é possível compreendê-la e estabelecer um dialogo com essa mulher, mas, o dialogo requer a presença do "outro" em sua vida. Dia após dia, vivenciando o cotidiano do asilo, as atividades, a rotina, e os eventuais "acidentes".

A pessoa que traduz o que Célia diz é alguém presente em sua vida; alguém que participa, ouve, observa e apreende a maneira de ser dessa mulher e das outras mulheres, estando autorizada a traduzir o que Célia tenta me dizer. Alguém que também sofre, no sentido de suportar as condições ou situações vividas com o "outro", a partir de um território e de um tempo.

Observo a relação dessas mulheres, que se comunicam através da realização de atividades em comum, em participação em eventos triviais, mas que geram cumplicidade, afetividade e compreensão. Nessa direção, é preciso destacar, com Teresa Caldeira, que embora:

a história de vida e o relato de história oral ofereçam informações imprescindíveis, não se podem ser pensados como fontes auto-suficientes. Tem que ser concebidos como elementos de um sistema de dados variados e que se articulariam no processo de reconstituição de uma determinada cultura ou da história de um determinado grupo social (CALDEIRA,1992, p. 71).

Nessa perspectiva surge a possibilidade de compreender e apreender sobre essas mulheres, não somente a partir de relatos, mas de registros,

12 Pesquisa realizada maio/2011. Documentos pesquisados no Serviço de Arquivo Médico e Estatístico -Same/ Hosmac e no arquivo do Lar Vicentino. 
documentos, e mais além, através do olhar atento, curioso, interessado, para além das palavras faladas e escritas, mas de maneira não-sistemática e fragmentada, "falando, ouvindo, observando, vivendo, juntando significados para se formar uma interpretação" (CALDEIRA, 1992, p. 69).

Aos poucos, mergulho nesse desconhecido e somente com o passar das horas, com infindáveis questionamentos, motivada por literaturas e leituras diversificadas, as quais transformaram e ampliaram minha imaginação, tão fundamental para compreender outras possibilidades vou apreendendo maneiras de narrar e interpretar mundos desconhecidos.

"Qualquer pesquisa antropológica é um processo contínuo de negociar diferenças entre o pesquisador e o grupo estudado, entre o que se pensava antes e o que se descobre no decorrer do encontro", destaca Caldeira (1992, p.70). Desse modo, reinicio o processo de interpretação, agora mais aprofundado, "procedendo a uma escavação", à maneira de Proust, de um modo mais significativo, porém, muito mais sutil, delicado, e por vezes imperceptível. Agora, olho com mais atenção para as pequenas lembranças e recordações.

\section{“Um copo d'água...”: apreendendo olhares, gestos e outras linguagens}

Realizo minha pesquisa durante o dia, posto que nos horários noturnos o Lar Vicentino cerra suas portas para os visitantes. Numa certa tarde, tranqüila e calma, com clima ameno, olho pela janela e vejo as mangueiras que rodeiam a casa, o quintal limpo, organizado. Alguns moradores aparecem para conversar ou solicitar algo. No "fundo da tarde", continuo lendo, anotando e imaginando.

Em meio aos registros dos prontuários, surge Elvira, que pede, à sua maneira, um copo para tomar água. As “informações” sobre sua trajetória são secas e frias. Nascida em 13 de agosto de 1952. Solteira; não alfabetizada; aposentada. Sua primeira internação no Hosmac data de 11 de novembro de 1978. Foi transferida para o Lar Vicentino em 6 de março de 2008. Mediante estudo de caso realizado pelo Serviço Social do Hosmac e decisão judicial. Segundo laudo médico expedido para solicitar sua aposentadoria: "é portadora de deficiência mental grave, pueril; deficiência física. É incapaz de exercer atividades 
laborativas para prover meios para sobrevivência. Necessita de benefício da Previdência Social". ${ }^{13}$

Procuro nos armários, encontro na geladeira apenas um copo de plástico para café e lhe ofereço. Elvira serve a água e saboreia, devolvendo o copo em seguida. Diz algo que não compreendo. Estamos a sós na sala, então ela pousa lenta e delicadamente sua mão sobre o meu peito, e depois, pousa sua mão em seu próprio peito, me diz novamente algo e sai, dirigindo-se ao seu quarto.

Seu gesto gentil e afetuoso me emociona e, com a passagem dos dias, compreendo o quão valoroso foi aquele momento, àquela imagem. Suas impressões e sensações me dizem muito. Mas não há palavras, apenas gestos simples e sinceros, repletos de ternura e atenção. Uma comunicação que desnuda meus pré-conceitos e me faz lançar um novo olhar para essa mulher sensível e inteligente a desafiar as noções "normalizadas", no dizer de Foucault (2008), instaladas em minha subjetividade, controlando meu olhar.

Percebo nesse momento que o que se coloca, portanto, no panorama dessa discussão é um poder disciplinador instituído como saber-poder. Um saber médico que, aliado a um saber jurídico, e, principalmente, a todo um aparato discursivo presente nas estruturas arquitetônicas de locais especiais asilos, hospitais psiquiátricos, prisões -, nas roupas, no corte dos cabelos e nos próprios corpos definem a condição de "alienação" a algumas pessoas que aí residem (FOUCAULT, 1999) e, neste caso, a mulheres como Elvira, tratada como incapaz de gerir sua própria vida ou "governar-se".

Que tipo de poder é esse, indaga Foucault, "capaz de produzir discursos de verdade que são numa sociedade como a nossa, dotados de efeitos tão potentes?" Em sociedades como a que vivemos, responde ele:

Múltipas relações de poder perpassam, caracterizam, constituem o corpo social; elas não podem dissociar-se, nem estabelecer-se, nem funcionar sem uma produção, uma acumulação, uma circulação, um funcionamento do discurso verdadeiro (...). Somos submetidos pelo poder à produção da verdade e só podemos exercer o poder mediante a produção da verdade (...). Temos de produzir a verdade como, afinal de contas, te-

Atestado pelo Dr. Mauro Hashimoto. Médico Psiquiatra do Hosmac. 
mos de produzir riquezas, e temos de produzir a verdade para poder produzir riquezas. E, de outro lado, somos igualmente submetidos à verdade, no sentido de que a verdade é a norma; é o discurso verdadeiro que, ao menos em parte, decide; ele veicula, ele próprio propulsa efeitos de poder. Afinal de contas, somos julgados, condenados, classificados, obrigados a tarefas, destinados a uma certa maneira de viver ou a uma certa maneira de morrer, em função de discursos verdadeiros, que trazem consigo efeitos específicos de poder. Portanto, regras de direito, mecanismos de poder, efeitos de verdade (FOUCAULT, 1999, pp. 28-29).

Essa lógica de produção da verdade e do poder, que é saber, me fez lançar um olhar de indiferença para as mulheres "doentes mentais" do Lar Vicentinos. Olhar que se alterou mediante a insistência de meus interlocutores quando do Exame de Qualificação, mas que se quebrou mediado por um toque de mãos, um simples toque de mãos, a comunicar com precisão e desenvoltura outros domínios da verdade. E esse domínio passa pela possibilidade do afeto e da socialização ou do contato com outra pessoa.

Percorro os desvãos de Elvira: suas dores, sua "insanidade", suas vontades violentadas. Observo-a sorrindo, colorindo papéis com a mesma meiguice com que carrega sua inseparável boneca: dorme com a boneca, almoça, passeia, vai ao médico, participa das aulas de artes e recreação, sempre acompanhada da boneca. Mas que boneca é essa? Que formas físicas e simbólicas ela desenha na imaginação e no dia-a-dia dessa mulher?

Sigo os "atalhos" de sua silenciada memória. Elvira foi residente do Hospital de Saúde Mental do Acre - Hosmac, durante muito tempo, antes de ser transferida para o Lar Vicentino. Naquele hospital de "alienados", pelos imprevisíveis caminhos do viver a vida, engravidou de outro residente. A criança, recém-nascida, foi entregue para adoção. Nesse processo, interceptada em sua capacidade de "auto-governo", Elvira passou a preencher esse outro vazio em sua vida e, como que em resposta à violência física e simbólica, desde então, passou a carregar a boneca/bebê em seu colo.

Observo a atitude resoluta dessa mulher que, de modo consciente, enfrenta a violência do poder disciplinador e da verdade do discurso mé- 
dico, jurídico, normalizados por nossos olhares, que lhe imputam a insanidade e a incapacidade de se governar, de ser sujeito de sua vida. Com a constante presença da boneca/bebê ao colo - erigida a símbolo de sua insanidade -, subverte a ordem de nosso discurso, de nosso saber-poder.

Com esse ato, Elvira não permite que o que lhe ocorreu se apague: é uma luta contra o esquecimento. Seu silêncio é carregado de gestos. Seus gestos são carregados de dor.

É necessário reconverter o silêncio em voz daqueles que viveram desde dentro o acontecimento. Os acontecimentos são concretos. O inumano é um acontecimento plural, ele não pode ser apenas mais uma figura que se perde na abstractização da dor (...). Sem a memória o homem seria sempre o espectro de sua liberdade. Estranho, ele seria apenas a materialidade de um presente em que todos os possíveis foram impossíveis. A liberdade não é para além da memória enquanto direito. Mas, "desde que os acontecimentos vividos pelo indivíduo ou pelo grupo sejam de natureza excepcional ou trágica, esse direito torna-se um dever: o de se lembrar, o de testemunhar" (VILELA, 2001, pp. 243-244).

Acompanhando essa inquietante reflexão de Eugênia Vilela, apreendemos que a constante e desafiadora presença da boneca/bebê no colo ou nos braços de Elvira, mais que um enfrentamento à ordem é um testemunho sem palavras das violências sofridas. Sua condição de mulher, mãe e "doente mental", está ali presente - a boneca no lugar do bebê ou, nas infinitas possibilidades de sua imaginação, o bebê no lugar da boneca -. Ela é incapaz, diz o laudo médico: “... é portadora de deficiência mental grave, pueril; e deficiência física. É incapaz de exercer atividades laborativas para prover meios para sobrevivência...”. ${ }^{14}$

No entanto seu gesto nos leva a pensar nas dimensões da memória e em sua capacidade de testemunhar, como forma de diálogo com o que não diz, o "indizível”, o vivido e com isso, retornando a Vilela, como mecanismo para a compreensão do acontecido:

É imprescindível deixar ser tocado (...). No testemunho, aquele que se manifesta passa a existir para além de um discurso legiti-

14 Laudo Médico. Dr. Mauro Hashimoto, 08/10/2008, Serviço de Arquivo Médico e Estatístico SAME. HOSMAC. Pesquisa feita em 31/01/2011. 
mado pelos jogos de verdade, uma vez que "a reconstituição do passado é percebida como um ato de oposição ao poder". As memórias são, afinal, uma cicatriz que dá sentido à ligação da vida e da morte (...). A memória é participação na verdade do mundo. Negamos a verdade àqueles a quem despossuímos da memória. Sem ela, a violência é a única possibilidade. Assim, ao incorporarmos a história do outro no presente, o outro deixa de ser uma inconsistência ontológica (VILELA, 2001, p. 245).

Nos gestos de Elvira, é possível antever uma irrupção contra a violência física e simbólica e contra a face mais amarga da violência, caracterizada por Bessa Freire (2004) como um "esquecer o esquecimento". Na construção que faz e nos silêncios e esquecimento há que muitas vezes somos levados e também nos permitimos sustentar, opõe-se à ordem das coisas e das palavras (FOUCAULT, 2007, p.20)

Elvira não se cala. Ao invés disso, sustenta a experiência vivida através de seus atos e gestos delicados e "controversos", suscitando questionamentos e curiosidades, indicando a presença de algo interrompido, proibido, interditado e descartado. Desnuda e traz à tona seu sofrimento, sua produzida "incapacidade". Leva com ela o "objeto/memória”, num deliberado e político ato de transgressão em que denuncia o que lhe foi escondido, não-permitido, retirado contra sua vontade; expõe sua dor aos olhos de todos, para não permitir o esquecimento.

Levando em consideração que as impressões, as lembranças, os esquecimentos estão em constante movimento, ou seja, que não há um passado imóvel, definitivo, o que podemos guardar do passado são impressões, sensações da experiência vivida; temos a necessidade de "escavar", mexer, re-atualizar o passado a partir do tempo presente, das precisões atuais. "Esquecer, assim como recordar, força-nos a selecionar, destilar, distorcer e transformar o passado, acomodando as lembranças às necessidades do presente" (LOWENTHAL, 1998, p.77).

A exemplo de Maurice Halbwachs, Lowenthal elucida que para relembrar o passado, acessar o arquivo de recordações, contamos com a memória individual, posto que é pessoal o que se vive, sente, imagina; e a me- 
mória coletiva o grupo social, como: família, amigos, colega de escola ou de trabalho, auxiliam na reconstrução, re-ordenamento e re-significação da memória individual: "partilhar e validar lembranças torna-as mais nítidas e estimulam sua emergência” (LOWENTHAL, 1998, p.80).

A boneca/bebê de Elvira faz com que a lembrança se mantenha presente, atualizada individual e coletivamente, pois, ela partilha com as pessoas com as quais convive, e com os outros que a observam, sua memória e condição "irrealizada" de mãe. Desse modo, consideramos com Lowenthal que:

As lembranças são reconstruções ecléticas, seletivas, baseadas em ações e percepções posteriores e em códigos que são constantemente alterados, através dos quais delineamos, simbolizamos e classificamos o mundo a nossa volta (LOWENTHAL, 1998, p.103).

Portanto, para lembrar é preciso selecionar, descartar, reorganizar novas maneiras de elaborar e construir reflexões sobre o vivido, trata-se do ato de pensar, de abstrair, construir simbologias, com o auxilio da imaginação. "As lembranças precisam ser continuadamente descartadas e combinadas; somente o esquecimento nos possibilita classificar e estabelecer ordem no caos" (LOWENTHAL, 1998, p. 94). Desse modo, interpreto no gesto de Elvira um ato de reflexão e construção de uma lembrança. Não algo "pueril, débil ou anormal", mas sim um ato de lembrar que exige imaginação, sensibilidade e ética na percepção do "outro".

Elvira, Cremilda, Célia, Marialva, Tereza, Marizete, Guiovanda, Terezina, Maria Adélia, Mariana, Maria, Romilda, Mirele e as outras mulheres interditadas do Lar Vicentino reabrem a ferida da condição feminina nos asilos, hospícios e hospitais-presídios brasileiros. Seus prontuários convencem os leitores, os familiares, os pesquisadores de que são "incapacitadas" para viver a vida "normal", mecanismo "normalizador" da internação, da tutela e da medicalização de seus corpos em nome de um bem-estar individual e coletivo.

Reside aí, em nossas subjetividades subordinadas às lógicas 
colonizatórias e mercadológicas, a força dessa "vontade de verdade", no dizer de Foucault, essa poderosa e

prodigiosa maquinaria destinada a excluir todos aqueles que, ponto por ponto, em nossa história, procuraram contornar essa vontade de verdade e recolocá-la em questão contra a verdade, lá justamente onde a verdade assume a tarefa de justificar a interdição e definir a loucura (FOUCAULT, 2006, p.20).

Acompanhando a cesura foucaultiana, ressalto que os corpos das mulheres do Lar Vicentino são corpos-denúncia a desafiar a verdade escrita de seus prontuários, clausuras e interdições. Suas vozes mudas, sua decantada "incapacidade" física e/ou mental atestam não o silêncio, mas a ruptura com o mesmo. São corpos cuja materialidade "não mentem", posto que marcados pelas misérias, violências e indignas condições de vida (SARLO, 2005).

Seus corpos testemunham e, no testemunho, como destaca Eugênia Vilela, "é necessária uma linguagem outra”, uma linguagem que ultrapasse "a linguagem humana dos nomes" e que dê sentido às coisas não ditas, mas nem por isso ausentes. Nessa "anti-linguagem", ou outra linguagem, do corpo e do gesto os corpos das mulheres - e os dos homens - do Lar Vicentino "não são os enunciadores de enunciados; são eles próprios a enunciação e o enunciado, justapostos" em seus corpos (VILELA, 2001, p. 249). Enunciação e enunciado denunciando e testemunhando suas condições de vida para um mundo indiferente e resignado. Enunciação e enunciado provocando inquietações, como o gesto de Elvira ao tocar minhas mãos e meu peito com afeto e seguir por entre corredores, salas e outros espaços do Lar Vicentino com sua boneca-bebê no colo. Um gesto que produz sentidos, re-significa trajetórias, desafia verdades.

\section{ReAdings ON THE FEMALE CONDition IN THE HOUSE OF THE VINCENTINIANS, IN RIO BRANCO, ACRE}

ABSTRACT: Resorting to documents collected from medical records, inventories and logs archived in the Hospital of Mental Health of Acre (HOSMAC), as well as data from 
admission forms and other documents archived in the individual files stored by the St Vincent de Paul Society, this work attempts to open a dialogue with the "silenced" voices of the women who live in the House of the Vincentinians (Lar Vicentino), in the city of Rio Branco, in the Acrean Amazon. The purpose of this dialogue is translating and understanding the senses and meanings of the stories of these women, in the aim of revealing the female condition in specific living conditions, in a refuge within a city which is being promoted as one of the best places in Northern Brazil in terms of quality of life.

KEYWOORDS: Female Condition. Life Journeys. Refuge. Rio Branco. Acrean Amazon.

\section{Referências}

BENJAMIN, W. Magia e técnica, arte e política: ensaios sobre literatura e historia da cultura. Tradução de Sergio Paulo Rouanet; prefácio Jean Marie Gagnebin. - 7. ed. - São Paulo: Brasiliense, 1994. - (Obras escolhidas; v. 1).

CALDEIRA, T. Memória e Relato: a Escuta do Outro. Revista do Arquivo Municipal Memória e Ação Cultural - São Paulo: DPHM, 1992.

FOUCAULT, M. A ordem do discurso. Tradução de Laura Fraga de Almeida Sampaio. São Paulo: Edições Loyola, 2006.

FOUCAULT, M. As palavras e as coisas: uma arqueologia das ciências humanas. Tradução de Salma Tannus Muchail. São Paulo: Martins Fontes, 2007.

FOUCAULT, M. Em defesa da sociedade. Tradução de Maria Ermantina Galvão. São Paulo: Martins Fontes, 1999.

FOUCAULT, M. Vigiar e Punir: nascimento da prisão; trad. de Raquel ramalhete. 35 ed. - Petrópolis, RJ: Vozes, 2008 - 288p.

FREIRE, J. R. B. Rio Babel - A história das línguas na Amazônia. Rio de Janeiro: Atlântica, 2004.

GINZBURG, C. O queijo e os vermes. O cotidiano e as idéias de um moleiro perseguido pela inquisição. Trad.: Maria Bethania Amoroso; tradução dos poemas: José Paulo Paes. - São Paulo: Companhia das Letras, 2006.

GONÇALVES FILHO, J. M. Memória e Sociedade. Revista do Arquivo Municipal Memória e Ação Cultural - São Paulo: DPHM, 1992.

HALBWACHS, M. Memória Coletiva. Tradução: Beatriz Sidou. São Paulo: Centauro, 2006, 224p. 
LOWENTHAL, D. Como conhecemos o passado? Projeto História: Revista do Programa de Estudos Pós-Graduados em História e do Departamento de História da PUC São Paulo n. 0 (1981) -; São Paulo: EDUC, 1981 - n. 17, novembro/1998.

PROUST, M. Em busca do tempo perdido. Tradução Fernando Py. - Rio de Janeiro: Ediouro, 2004.

SARLO, B. Tempo passado: cultura da memória e guinada subjetiva; trad. Rosa Freire d'Aguiar. - São Paulo: Companhia das Letras; Belo Horizonte: UFMG, 2007.

SARLO, B. Tempo Presente. Notas sobre a mudança de uma cultura. Trad.: Luis Carlos Cabral. Rio de Janeiro: José Olympio, 2005.

VILELA, E. "corpos inabitados. Errância, filosofia e memória”, In: LARROSA, J. \& SKLIAR, C. Habitantes de Babel: políticas e poéticas da diferença. Tradução de Semíramis Gorini da Veiga. Belo Horizonte: Autêntica, 2001, pp. 233-253.

Data de recebimento: 10/10/2014

Data de aceite: 12/11/2014 